To cite this article (IEEE): S. Ribeiro-Carvalho, A. Horovistiz, and J. P. Davim, "Material model assessment in Ti6Al4V machining simulations with FEM," Proc. Inst. Mech. Eng. Part C J. Mech. Eng. Sci., p.

095440622199488 , Feb. 2021, doi: 10.1177/0954406221994883.

\title{
Material model assessment in Ti6Al4V machining simulations with FEM
}

\author{
Sílvia Ribeiro Carvalho*, Ana Horovistiz, J. Paulo Davim
}

TEMA, Department of Mechanical Engineering, University of Aveiro, Campus of Santiago, 3810-193

$$
\text { Aveiro, Portugal }
$$

*Corresponding author: Tel- +351 234370 830; fax-+351 234370 985; E-mail address: sdrc@ua.pt

Abstract: Ti6Al4V alloy is a well-known difficult-to-cut material used in different industrial applications, to achieve the expected component quality, proper definition and control of the machining process parameters must be accomplished. To address this problem, simulations with finite element method (FEM) seem to be an interesting engineering tool to model and optimize machining processes. Nevertheless, the model capability in capturing the behaviour observed in real machining processes is associated with the definition of the model and parameters that describe the workpiece flow stress. This contribution aimed to study the performance of built-in AdvantEdge-2 $\mathrm{D}^{\mathrm{TM}}$ material laws applied in Ti6Al4V orthogonal cutting simulations under dry conditions. The numerical models were created under three levels of cutting speed, a constant feed rate and depth-of-cut, a variable tool rake angle (of $20^{\circ}$ and $-6^{\circ} / 0$ $\left.{ }^{\circ}\right)$, but also using four Ti6Al4V constitutive laws, namely, one suggested in AdvantEdge ${ }^{\mathrm{TM}}$ library, a JohnsonCook (JC) model, a Power law (PL) and a PL coupled with ductile damage model. Experimental results were used to assess the numerical models accuracy in predicting the machining forces and metal chips. Satisfactory results regarding the machining forces prediction were achieved with all material laws, yet when the damage criterion was coupled with the constitutive laws (PLD and AE standard material law), the simulations were also were able to achieve the expected chip morphology (serrated metal chips). 
Keywords: Ti6Al4V, AdvantEdge, orthogonal cutting, power law, Johnson-Cook material model, machining forces, saw-tooth chips.

\section{Introduction:}

Ti6Al4V alloy is often selected for high-value applications in the aerospace, automotive, and biomedical manufacturing sectors, due to its excellent combination of properties including high strength-to-weight ratio, corrosion resistance and biocompatibility [1]. Although these industries have different demands regarding productivity and properties of the manufactured parts, all of them use machining processes to fabricate components, and for that reason, process optimization and control is needed for fulfilling the product quality requirements [2]. Nevertheless, monitoring, controlling, and predicting machining behaviour can be a challenging task due to the intricate relationship between the input variables and the response generated during machining [3]. Moreover, for Ti6Al4V alloy, there are specific challenges, related with intrinsic material characteristics, such as low thermal conductivity and severe work hardening capability, that must be mitigated, by defining suitable process conditions, for improving the surface integrity, increase the tool life and meet productivity and sustainability standards [2]. Typically, in machining, the input variables are the operation parameters, the aspects of the tool, the presence of cutting fluids, as well as the properties of the workpiece material. The parameters combination will produce a response (temperature gradient, forces, vibrations) that can be monitored during the process (experimentally and/or numerically), or by evaluating the outcomes of the tribological system, namely the machined surface, tool, and chips. Modelling and optimization algorithms can be applied to the inputoutput database to understand how to improve the process [3]. A drawback of this approach is that consumes a substantial amount of time and resources since numerous combinations of cutting parameters are typically tested and repeated [4]. Numerical simulation with FEM has proven to be a reliable tool in defining operating parameters and reducing the number of conditions that need to be 
tested experimentally to achieve a specific goal, that can extend the tool life, select proper tool geometries, reduce the residual stress [4]-[7]. Besides, some authors argue that FEM simulation can be a practical tool to estimate certain variables, such as, cutting forces, workpiece residual stress [6], [8], cutting tool stress [9], chip morphology and breakability [10]-[12], the temperature distribution in the workpiece, cutting tool [13] and metal chip [14]-[16], that can be problematic to measure experimentally, or that require specific equipment to do so, for example, dynamometers [10], [17], diffractometers [6], high-speed cameras [18], thermocouples [19] and thermal cameras [20], [21]. In some cases, these variables are quantified experimentally and compared with the numerical results to validate the numerical approach.

Developing trustworthy predictive models, based on FEM simulation, that can be used for improving industrial machining processes is a goal in the current and future investigation scenario [3]. In this scope, several authors have been focusing attention on investigating the flow stress laws and parameters that describe the thermo-viscoplastic behaviour of the workpiece during machining simulations. A common concern is how the constitutive law deals with the metal chip formation, especially for exotic alloys, such as Ti6AI4V, Inconel 718 and AISI D2, that tend to produce saw-tooth chips [7]. In 2019, Stolf et al. [22] simulated orthogonal cutting (OC) operations in Ti6Al4V alloy under high-pressure coolant conditions. The authors used AdvantEdge ${ }^{\mathrm{TM}}(\mathrm{AE})$ to create the FEM models and refer that a power law (PL) was used to simulate the workpiece behaviour under machining conditions. Although in the paper, the PL formulation is presented, the parameters are absent, also, the numerical results suggested the formation of serrated chips, therefore, seems that a damage criterion was coupled into the PL. Perhaps this means that the AE standard model was used to model Ti6Al4V alloy under machining conditions. A major disadvantage of using this method is that the model and parameters are chosen by the AE solver and are unavailable to the user, also, the user cannot utilize data from mechanical testing to define the model parameters. One way to outcome this constraint is to create an AE custom material (as an alternative to standard) using 
the AE built-in model for the power law with damage (PLD) and then manually define the parameters. This approach was reported by Jiang et al. [23] to simulate the metal chips formed in OC operations with AISI D2 alloy. Another solution may be, by formulating the constitutive law and damage criterion in Fortran routines an implement them in $A E$ software. This method is more flexible, yet more demanding in terms of programming skills that the user must-have. This approach was reported by Ortiz-De-Zarate et al. [18] that developed a set of FEM simulations for a Ti6Al4V broaching operation, where they tested the performance of three constitutive laws specifically a power law (PL), a Johnson-Cook (JC) material model [24] and constitutive law proposed by Iturbe et al. [25] for Inconel 718. All the constitutive laws were coupled with a ductile failure model. The details regarding the implementation of the failure criterion are described in Childs [14] and Zarate [26]. The authors concluded that the three laws had a similar capability in predicting the cutting forces, as well as in reproducing the segmentation of the metal chip that happened during the experimental tests. In a work from 2020, the same coupled JC model was used to study the surface drag effect in surfaces obtained in OC operations under different cutting conditions [27].

Other FEM models that successfully predicted the sawtooth chip morphology were created in other simulation packages. In 2016, Lu et al. [28] employed a JC model coupled with Crock and Latham's (CL) failure criterion in DEFORM-2D ${ }^{\mathrm{TM}}$ to study the burr formation mechanism in Ti6AI4V OC operation. Similar modelling strategy was applied by Ortiz-de-Zarate et al. [29] in 2018, the authors conducted numericalexperimental work to study the thickness of the deformed layer and the maximum residual compression stress in machined surfaces. They used models were created in DEFORM-2D ${ }^{\mathrm{TM}}$ using a JC law coupled with $\mathrm{CL}$ failure criterion. The models predicted with accuracy the cutting forces and chip morphology observed in experimental tests. In 2017, Li et al. [30] used Abaqus ${ }^{\mathrm{TM}}$ to model OC operation in Ti6Al4V to study surface integrity aspects, namely, workpiece plastic strain and strain rate. They applied a JC law in conjunction with a JC fracture to model the workpiece material. The experimental-numerical forces and metal chips morphology were used to attest the reliability of the FEM models. The use of the JC law with 
$\mathrm{JC}$ damage criterion is extensively reported in the literature, especially when using Abaqus ${ }^{\mathrm{TM}}$ software for performing 2D [10], [31] and 3D [12], [32] simulations. In the research works referred until now, the serrated chips were mostly formed by coupling a damage model to the constitutive law, yet in some cases, authors that proposed modifications into the constitutive models and/or explore different FEM formulations to account with the shear banding effect [7]. This type of approach was reported, for example, by Ducobu et al. in 2014 [11] that used Abaqus-Explicit ${ }^{\text {TM }}$ to simulate OC operations in Ti6Al4V alloy using two constitutive laws, a JC model and TANH law [33] (which is an upgrade of the JC model, that accounts with material strain-softening effect) along with two types of FEM formulations, a Lagrangian (LAG) and an Arbitrary Lagrangian-Eulerian (ALE). The authors concluded that the TANH law by itself promoted the formation of saw-tooth chips, especially when using the LAG formulation, that includes crack propagation effect. An analogous conclusion was taken by Zhang et al. [10] that stated that a JC model coupled with the JC damage model was only capable of predicting serrated metal chips in Abaqus-Explicit ${ }^{\mathrm{TM}}$ when LAG formulation was used, instead of ALE and Couple Lagrangian-Eulerian (CEL). From the state-of-the-art assessment, it was possible to understand that, when doing machining simulation with FEM, different methodologies for the workpiece material law definition can be used, with accurate results in predicting the machining forces and metal chip morphology. The simulation software capabilities, including the FEM formulation, the available material laws, the possibility of implementing user-defined material laws must be considered when developing numerical models, without disregarding that straightforward methods with relevant industrial outputs are expected for industry 4.0 implementation.

In this work, Ti6Al4V alloy OC simulations were developed using built-in material laws available in AdvantEdge-2D ${ }^{\mathrm{TM}}$ (Ti6Al4V standard model and user-defined JC, PL and PLD). The research focus was to assess how the workpiece constitutive law affected the simulation accuracy in predicting the machining forces, power, temperature and chip morphology considering OC experiments reported in [21]. The work 
development also included the evaluation of the thermomechanical response when using tools with distinct rake angles since it is a key criterion when defining machining conditions. This work intended to tackle a gap, which was the lack of Ti6AI4V OC models developed in AE using the available built-in material models, as well as the comparative performance assessment of each modelling approach.

\section{Ti6Al4V alloy orthogonal cutting: Description of the numerical approach}

In this section, the methodology behind the development of the orthogonal cutting models for Ti6Al4V alloy in AdvantEdge-2DTM will be presented. Some simulation aspects were defined accordingly with the cutting settings reported by Nouari and Makich [21], these authors conducted orthogonal cutting tests in Ti6Al4V alloy under dry conditions using TiAIN coated tools with a coating thickness of $4 \mu \mathrm{m}$, the inserts were made of cemented carbide with the thermo-mechanical properties described in Table 1. Additionally, the cutting tests were performed with two types of cutting inserts, Geometry A and B as displayed in Figure 1 (a) and (b), respectively. The tools had the same a flank angle $\left(7^{\circ}\right)$ and a cutting edge radius of $20 \mu \mathrm{m}$. The machining tests [21] were carried out with a constant depth of cut of $3.5 \mathrm{~mm}, \mathrm{a}$ constant feed rate of $0.1 \mathrm{~mm} / \mathrm{rev}$, and with three levels of cutting speed, 20,35 , and $65 \mathrm{~m} / \mathrm{min}$.
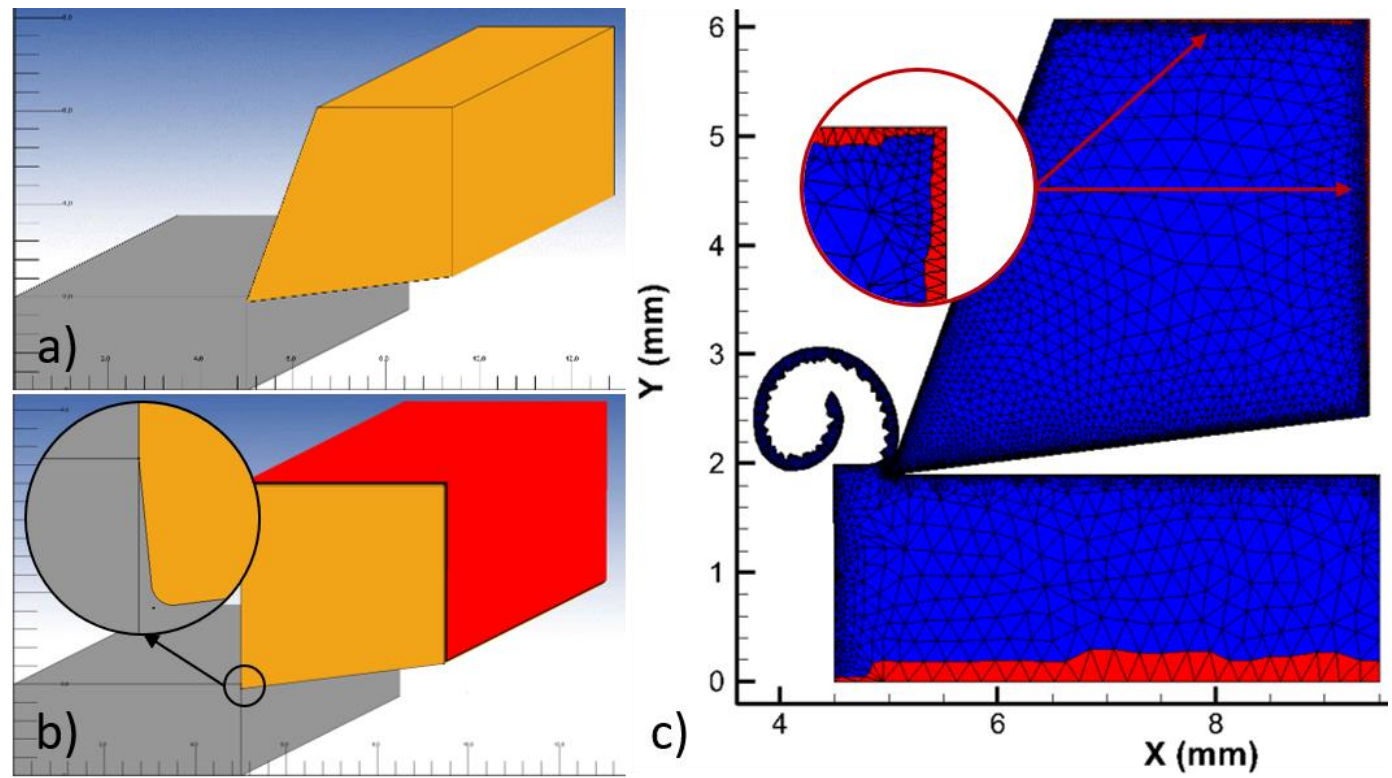
Figure 1. In (a) geometry A, the tool was created as an AE standard tool with a positive rake angle of $20^{\circ}$. In (b) geometry $B$, the tool was defined as an $A E$ custom tool, with a double rake angle with neutral $\left(0^{\circ}\right) /$ negative $(-$ $6)^{\circ}$ configuration. The thermo-mechanical boundary conditions applied to the tools are also represented. In (c) the mesh that was used to discretize the model, but also the mechanical boundary conditions applied in the workpiece and tool.

Concerning the mechanical boundary conditions adopted for the numerical models, it is possible to observe in Figure 1 (c), that the bottom side of the workpiece is fixed in the cutting and feed direction, while the cutting tool is constrained in the top and right side (black contour in Figure 1 (b) and red regions in Figure 1 (c)). This way, the tool movement occurs at a constant velocity along the workpiece.

In Figure 1 (b), the tool thermal boundary conditions applied in the numerical models were displayed. These conditions were defined accordingly to the literature [28], as well as with the indications provided in the AE user manual [34]. The upper and right regions at red were kept at a constant temperature of $20^{\circ} \mathrm{C}$, while the other tool surfaces allow heat transference between the workpiece and tool. The visualization of the thermo-mechanical boundary conditions was only presented for geometry B because a customized tool was created to include the double rake angle, and for that reason, the boundary conditions are defined by the user and appear in the cutting tool representation, yet tool geometry $\mathrm{A}$ and B have the same thermo-mechanical boundary conditions.

Regarding the meshing strategy, in AE simulation environment, the mesh is updated in every iteration to accommodate the high deformation regions, however, the machining model is always discretized using six-nodded quadratic triangular elements as represented in Figure 1 (c)[35]. In this work, the workpiece mesh contained a maximum number of nodes of 24000 . The minimum and maximum element size for the workpiece and tool were the same 0.02 of $0.2 \mathrm{~mm}$, respectively.

\subsection{Workpiece material model definition}

As mentioned earlier, a goal for this research work was to compare, in terms of thermo-mechanical response, the performance of distinct workpiece material models to define Ti6Al4V behaviour under 
machining conditions. The material laws applied in the scope of this work were, the AE standard model for Ti6Al4V, the JC material model [24], a power law (PL) and a PL with damage criterion. The last three models are built-in in $\mathrm{AE}$, meaning that the model formulation is available in AE libraries, yet for each law, certain parameters must be inputted as shown in Table 3.

Table 1 contains the thermomechanical properties of the Ti6Al4V workpiece used when modelling the material as a user-defined material (JC, PL, PLD). The properties of the cutting insert (Table 1) were inputted for all the material models.

Table 1. Thermo-mechanical properties for workpiece and tool material [21].

\begin{tabular}{|l|l|l|}
\hline Property & Ti6Al4V & WC-Co \\
\hline Thermal conductivity $\left[\mathrm{W} / \mathrm{m} .{ }^{\circ} \mathrm{C}\right]$ & Table 2 & 45 \\
\hline Heat capacity $\left[\mathrm{J} / \mathrm{Kg} .{ }^{\circ} \mathrm{C}\right]$ & 709 & 226 \\
\hline Density $\left[\mathrm{Kg} / \mathrm{m}^{3}\right]$ & 4430 & 11400 \\
\hline Alpha $\left[1 /{ }^{\circ} \mathrm{C}\right]$ & $1 \mathrm{E}-05$ & - \\
\hline Young Modulus $[\mathrm{GPa}]$ & 110 & 620 \\
\hline Poisson & 0.3 & 0.26 \\
\hline
\end{tabular}

Table 2 comprises thermal conductivity measurements for the Ti6Al4V alloy reported in the experimental setup used to validate the simulations conducted in this work [21]. Those values were entered in the numerical models to improve the similarity between the simulated material and the real one.

Table 2. Measurements of thermal conductivity for Ti6Al4V [21].

\begin{tabular}{|l|c|c|c|c|c|c|c|c|c|c|c|c|}
\hline $\begin{array}{l}\text { Temperature } \\
{\left[{ }^{\circ} \mathrm{C}\right]}\end{array}$ & 20 & 39 & 95 & 151 & 203 & 262 & 318 & 371 & 427 & 481 & 539 & 698 \\
\hline $\begin{array}{l}\text { Thermal conductivity } \\
{\left[\mathrm{W} / \mathrm{m} .{ }^{\circ} \mathrm{C}\right]}\end{array}$ & 7.3 & 7.3 & 7.4 & 8.1 & 8.7 & 9.3 & 10.2 & 11.1 & 11.5 & 12.5 & 13.3 & 14.8 \\
\hline
\end{tabular}

In the scope of this work, the Johnson-Cook plasticity model [36], the power law and the power law with damage were implemented using the parameters from Table 3. To define the ductile failure model for the PLD model literature on the field was consulted [14], [16], [18] and strain at failure of 0.2 was considered.

Table 3. Material model parameters used to simulate Ti6Al4V alloy machining [37], [38].

\begin{tabular}{|l|l|l|l|}
\hline \multicolumn{3}{|c|}{ Johnson-Cook } & \multicolumn{2}{c|}{ Power-law } \\
\hline $\mathrm{A}[\mathrm{Pa}]$ & $9.68 \mathrm{E}+08$ & $\sigma_{0}[\mathrm{~Pa}]$ & $9.52 \mathrm{E}+08$ \\
\hline
\end{tabular}




\begin{tabular}{|l|l|l|l|}
\hline $\mathrm{B}[\mathrm{Pa}]$ & $3.80 \mathrm{E}+08$ & $\mathrm{ep}_{\mathrm{n}}$ & 22.19 \\
\hline $\mathrm{n}$ & 0.421 & $\varepsilon^{\mathrm{p}_{0}}$ & 0.035 \\
\hline Room temperature $\left[{ }^{\circ} \mathrm{C}\right]$ & 20 & $\varepsilon^{\mathrm{p}}$ cut & 0.12 \\
\hline Melting temperature $\left[{ }^{\circ} \mathrm{C}\right]$ & 1655 & $\mathrm{c}_{0}$ & 1.822 \\
\hline $\mathrm{m}$ & 0.577 & $\mathrm{c}_{1}$ & $-5.71 \mathrm{E}-03$ \\
\hline $\mathrm{c}$ & 0.0197 & $\mathrm{c}_{2}$ & $1.7 \mathrm{E}-05$ \\
\hline rate 0 & 1 & $\mathrm{c}_{3}$ & $-2.164 \mathrm{E}-08$ \\
\hline & & $\mathrm{c}_{4}$ & $6.48 \mathrm{E}-12$ \\
\hline
\end{tabular}

\subsection{Friction coefficient definition}

In AdvantEdge, the friction between the tool-chip interface is governed by the Coulomb law presented in equation 1 , where $N[N]$ is the normal force between the surfaces, $\mu$ is the coefficient of friction and $F[N]$ is the resulting force due to friction. In AE software, the user can define the friction coefficient, by inputting a value between 0 and 1 or by selecting a default value which is decided by the solver [34].

In this research work, the friction force, the normal force, and the friction coefficient were calculated respectively, using equations 2,3 and 4 , considering that $F_{f}[N]$ is the feed force, $F_{c}[N]$ is the cutting force and $\alpha\left[^{\circ}\right]$ is the rake angle of the cutting tool. The previous expressions were obtained from the Merchant model for orthogonal cutting [39].

$$
\begin{aligned}
& F=\mu \times N \\
& F=F_{c} \sin \alpha+F_{f} \cos \alpha \\
& N=F_{c} \cos \alpha-F_{f} \sin \alpha \\
& \mu=\frac{F}{N}=\frac{F_{f}+F_{c} \tan \alpha}{F_{c}-F_{f} \tan \alpha}
\end{aligned}
$$

Using equations 2, 3 and 4 along with the experimental cutting and feed force values [21], it was possible to calculate the friction force, the normal force and the friction coefficient in the tool-chip interface for the geometry A and B, those values are presented at Table 4. From Table 4 analysis, it was possible to observe that, with the increase of the rake angle from $0^{\circ}$ to $20^{\circ}$, the experimental cutting and feed forces 
decreased, therefore it was expected that the friction between at the tool-chip interface also decreased, instead Table 4 content indicates that $\mu$ increases when the rake angle increases. This can be clarified when observing the normal force on the rake face $(\mathrm{N})$. At the cutting speed of $65 \mathrm{~m} / \mathrm{min}$, for example, when the rake angle increases from $0^{\circ}$ to $20^{\circ}$ the normal force decreases $50 \%$, while the friction force decreases $15 \%$, therefore the normal force on the rake face decreases a lot more than the friction force. This trend is observed for the other cutting speeds. For this reason, although the cutting forces decreased with the increase of the rake angle, the coefficient of friction increased [40].

Table 4. Friction coefficient values for all the cutting speeds.

\begin{tabular}{|l|c|c|c|c|c|c|c|c|c|c|c|}
\hline Tool Geometry & \multicolumn{5}{|c|}{ A: rake angle of $20^{\circ}$} & \multicolumn{5}{c|}{ B: rake angle $0^{\circ}$} \\
\hline & & Fc & Ff & F & $N$ & $\mu$ & Fc & Ff & F & N & $\mu$ \\
\hline \multirow{3}{*}{ S.I Units } & \multicolumn{6}{|c|}{$[\mathrm{N}]$} & & - & \multicolumn{5}{|c|}{$[\mathrm{N}]$} \\
\hline \multirow{3}{*}{ Speed (m/min) } & 20 & 745 & 267 & 506 & 609 & 0.83 & 950 & 510 & 510 & 950 & 0.54 \\
\cline { 2 - 13 } & 35 & 665 & 254 & 466 & 538 & 0.87 & 925 & 510 & 510 & 925 & 0.55 \\
\cline { 2 - 12 } & 65 & 602 & 243 & 434 & 483 & 0.9 & 960 & 510 & 510 & 980 & 0.53 \\
\hline
\end{tabular}

In conclusion, for this work, a total of 24 simulations were performed, considering, two tool geometries ( $A$ and $B$ ), three levels of cutting speed, four material models as summarized in Table 5 . The friction coefficient selected to perform the simulations with the tool geometry A and B was chosen based on the results presented in Table 4.

Table 5. Simulation Parameters

\begin{tabular}{|l|l|}
\hline Cutting speed & 20,35 and 65 [m/min] \\
\hline $\begin{array}{l}\text { Ti6Al4V material } \\
\text { models }\end{array}$ & Standard (S); Johnson-Cook (JC); Power Law (PL); Power Law with Damage (PLD) \\
\hline Friction Coefficient & $\begin{array}{l}\text { Tool geometry A: } 0.85 \\
\text { Tool geometry B: } 0.55\end{array}$ \\
\hline
\end{tabular}

\section{Results and Discussion:}

After submitting the simulations, the results were analysed using Tecplot, which allows the user to visualize important machining responses through a contour, which is an image of the workpiece, tool, and metal chip, where it is possible to see the chip and workpiece plastic strain, the heat rate, the stress, and 
others. The montage in Figure 2 contains the contours for the plastic strain obtained for both tool geometries, for all the tested models. Tecplot also provides a time history graph, with the forces, power, tool peak temperature along the machining time/cutting length, an example for the machining forces is presented in Figure 3. 

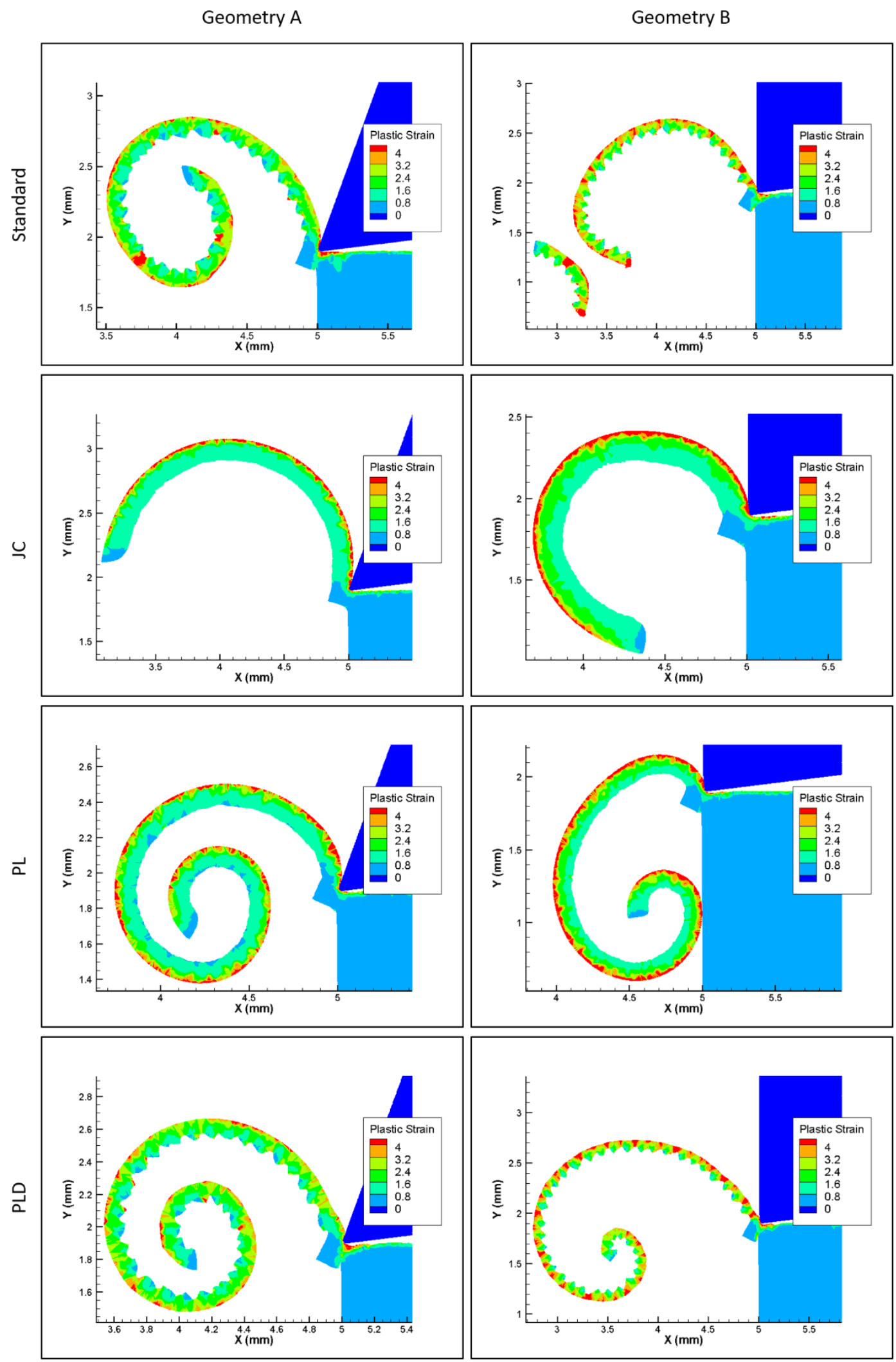

Figure 2. Chip plastic strain, for all the material models, for both geometries at a cutting speed of $65 \mathrm{~m} / \mathrm{min}$. 
From Figure 2 analysis it is possible to observe that the morphology of the chips changed a lot according to the workpiece material model. For instance, the standard model and the power-law model with damage were able to capture the serrated metal chips that are formed when machining Ti6Al4V alloy. This effect was not detected in the simulations conducted with the Johnson-Cook material model and the power law model. This can be explained by the fact that both models were not coupled with damage criterion, responsible for generating the sawtooth metal chips in Ti6Al4V simulations. Additionally, from Figure 2 observation it was possible to see that the tool with a positive rake angle (geometry A) provides a sharper cutting edge, which conducted to less metal chip deformation when compared with geometry $B$, where the regions with maximum deformation (at red) are higher.

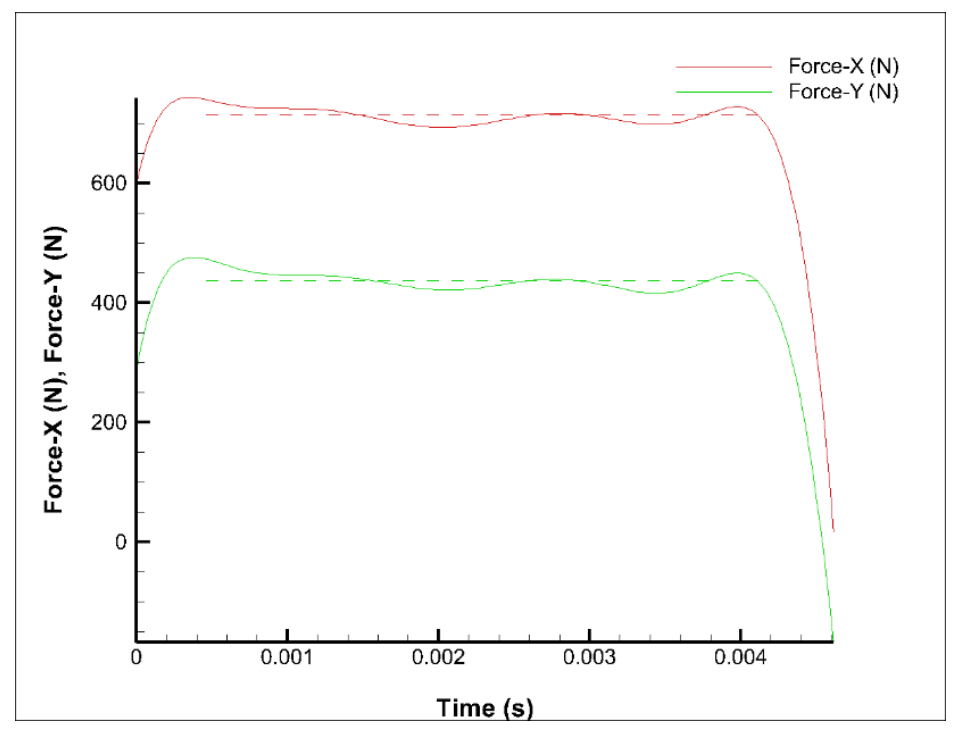

Figure 3. Variation of the machining forces obtained by simulating Ti6Al4V standard material under a cutting speed of $65 \mathrm{~m} / \mathrm{min}$ using geometry $B$ insert. $X$ is the cutting force, while $Y$ is the feed force. The average values for each force component are also represented.

\subsection{Machining forces analysis}

The average value of the numerical machining forces for each simulation was obtained as described in Figure 3 and was used to create the graphs in Figure 4, where it is possible to observe the cutting and feed forces predicted for each material model, for both tool geometries, at three levels of cutting speed, also, the experimental machining forces were also plotted. 


\section{Geometry A $\left(20^{\circ}\right) ; \mu=0.85$}

(a)

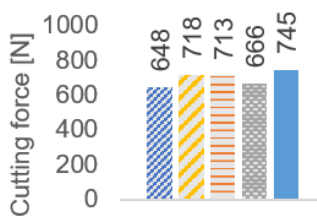

20

Cutting speed [m/min]

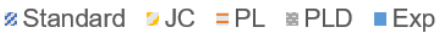

(b)

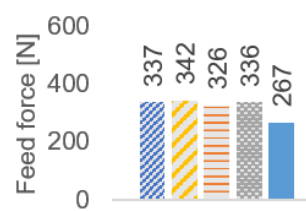

20

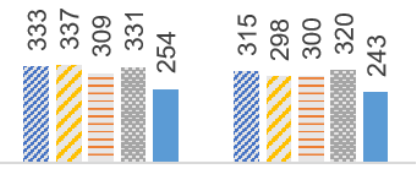

35

Cutting speed [m/min]

ฉ Standard $\square \mathrm{JC} \equiv \mathrm{PL}$ : $\mathrm{PLD} \square \operatorname{Exp}$

\section{Geometry B $\left(-6 / 0^{\circ}\right) ; \mu=0.55$}

(c)

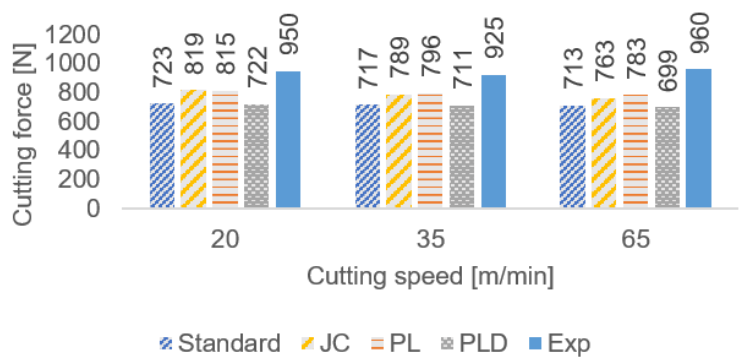

(d)

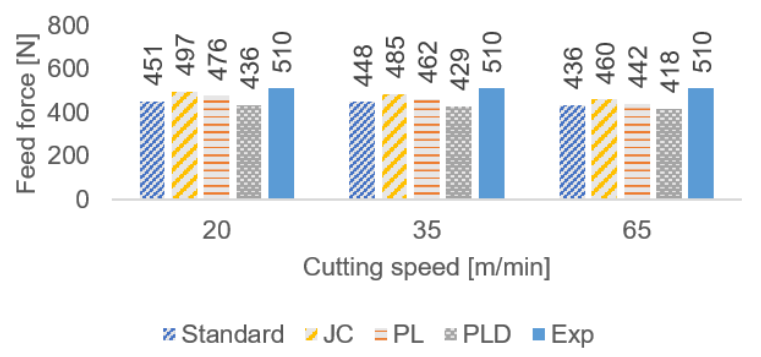

Figure 4. Cutting force $[\mathrm{N}]$ for geometry $\mathrm{A}(\mathrm{a})$ and geometry $\mathrm{B}(\mathrm{c})$; Feed force $[\mathrm{N}]$ for geometry $\mathrm{A}(\mathrm{b})$ and geometry $B(d)$ for all the tested conditions.

To quantify the difference between the predicted forces and the experimental ones, the percentual relative error was calculated for each modelled condition, using equation 5 , the results are presented in Table 6. Moreover, to evaluate the global capability that each material modelling approach had to predict the machining forces, the average percentual error (APE), which is the mean of the percentual relative error for the cutting and feed force was also calculated and it is also displayed in Table 6.

$$
\text { Error }=\frac{\left|F_{\text {num }}-F_{\text {exp }}\right|}{F_{\text {exp }}} \times 100
$$


Table 6. Percentual relative error (\%) between experimental and simulated cutting and feed force for both geometries and cutting speeds, as well as the average percentual error (APE) for machining forces (\%).

\begin{tabular}{|c|c|c|c|c|c|c|c|c|c|}
\hline & \multicolumn{9}{|c|}{ Geometry A } \\
\hline & \multicolumn{3}{|c|}{ Cutting force } & \multicolumn{3}{|c|}{ Feed Force } & \multicolumn{3}{|c|}{ APE } \\
\hline & 20 & 35 & 65 & 20 & 35 & 65 & 20 & 35 & 65 \\
\hline S & 13.0 & 2.7 & 4.3 & 26.2 & 31.1 & 29.6 & 19.6 & 16.9 & 17.0 \\
\hline $\mathrm{JC}$ & 3.6 & 5.1 & 10.6 & 28.1 & 32.7 & 22.6 & 15.9 & 18.9 & 16.6 \\
\hline PL & 4.3 & 3.8 & 11.8 & 22.1 & 21.7 & 23.5 & 13.2 & 12.7 & 17.6 \\
\hline \multirow[t]{4}{*}{ PLD } & 10.6 & 1.7 & 6.0 & 25.8 & 30.3 & 31.7 & 18.2 & 16.0 & 18.8 \\
\hline & \multicolumn{9}{|c|}{ Geometry B } \\
\hline & \multicolumn{3}{|c|}{ Cutting force } & \multicolumn{3}{|c|}{ Feed force } & \multicolumn{3}{|c|}{ APE } \\
\hline & 20 & 35 & 65 & 20 & 35 & 65 & 20 & 35 & 65 \\
\hline$S$ & 23.9 & 22.5 & 25.7 & 11.6 & 12.2 & 14.5 & 17.7 & 17.3 & 20.1 \\
\hline $\mathrm{JC}$ & 13.8 & 14.7 & 20.5 & 2.5 & 4.9 & 9.8 & 8.2 & 9.8 & 15.2 \\
\hline $\mathrm{PL}$ & 14.2 & 13.9 & 18.4 & 6.7 & 9.4 & 13.3 & 10.4 & 11.7 & 15.9 \\
\hline PLD & 24.0 & 23.1 & 27.2 & 14.5 & 15.9 & 18.0 & 19.3 & 19.5 & 22.6 \\
\hline
\end{tabular}

Table 6 indicates that, for geometry A, all the workpiece material models estimate properly the cutting force for all the cutting speeds. The maximum percentual relative error (PRE) was $13 \%$ for the standard model at cutting speed of $20 \mathrm{~m} / \mathrm{min}$, while the minimum PRE was 1.7 for the PLD model at a cutting speed of $1.7 \%$. However, as shown in Figure 4 (b), all the material models overestimated the feed force. The maximum PRE for the feed force was obtained with the JC model $(32.7 \%)$ at a cutting speed of $35 \mathrm{~m} / \mathrm{min}$, followed by the PLD model (31.7\%) at a cutting speed of $65 \mathrm{~m} / \mathrm{min}$. The minimum PRE was attained at 35 $\mathrm{m} / \mathrm{min}$ for the PL model. Regarding the global results for the machining forces prediction, for geometry $\mathrm{A}$, the minimum APE was achieved with the PL model, with a value of $12.7 \%$ and $13.2 \%$ for a cutting speed of 35 and $20 \mathrm{~m} / \mathrm{min}$, respectively. For the cutting speed of $65 \mathrm{~m} / \mathrm{min}$, the $\mathrm{JC}$ model presented the lower APE for the machining forces $(16.6 \%)$. The maximum APE was reached when using the standard material model (19.6\%) with a cutting speed of $20 \mathrm{~m} / \mathrm{min}$.

For geometry B, all the numerical models underestimated the feed force, as well as the cutting forces for all the material laws and cutting speeds as shown in Figure 4 (c) and (d). Yet, all the models were better 
at predicting the feed force than the cutting force, as demonstrated in Table 6. The maximum PRE for the feed force was $18 \%$ for the PLD model at cutting speed of $65 \mathrm{~m} / \mathrm{min}$. The JC model presented good results regarding the feed force prediction, for all the cutting speeds, with a maximum PRE of $9.8 \%$ and a minimum PRE of $2.5 \%$. regarding the cutting forces, the maximum PRE was reached with the PLD model at a cutting speed of $65 \mathrm{~m} / \mathrm{min}(27.2 \%)$, while the best predictions of the cutting forces were attained with the JC model at a cutting speed of $20 \mathrm{~m} / \mathrm{min}(13.8 \%)$ and with PL model at a cutting speed of 35 $\mathrm{m} / \mathrm{min}(13.9 \%)$. For geometry $\mathrm{B}$, the minimum APE for the machining forces was achieved with the JC material model ( $8.2 \%$ for $20 \mathrm{~m} / \mathrm{min}, 9.8 \%$ for $35 \mathrm{~m} / \mathrm{min}$ ). At $65 \mathrm{~m} / \mathrm{min}$, the minimum APE of the machining forces was attained with the PL model (15.2\%), yet this result is very similar to the one obtained with JC model (15.9\%). The maximum APE for the machining forces was obtained with the PLD (19.3\% for 20 $\mathrm{m} / \mathrm{min}, 19.5 \%$ for $35 \mathrm{~m} / \mathrm{min}, 22.6 \%$ for $65 \mathrm{~m} / \mathrm{min}$ ), followed by the standard material model $(17.7 \%$ for $20 \mathrm{~m} / \mathrm{min}, 17.3 \%$ for $35 \mathrm{~m} / \mathrm{min}, 20.1 \%$ for $65 \mathrm{~m} / \mathrm{min})$ ). Both JC and PL model presented satisfactory results in predicting the machining forces for all the tested conditions, the $\mathrm{JC}$ model was more accurate for geometry B, while the PL was better for geometry A. However, those models do not capture the serrated metal chips that occur during Ti-6Al-4V machining, as shown in Figure 2.

Another aspect that can be seen in the graphs from Figure $4(a)$ and (b) is that, for geometry A, the simulated cutting and feed forces, for all the material models followed the trend presented by the experimental results. The experimental results indicate that increasing the cutting speed promotes a decrease in the cutting and feed force, this is also noted in the numerical results. This behaviour can be explained by the material phenomena of thermal softening reported experimentally and numerically by several authors [28], [41]. When the cutting speed is higher, the temperature in the cutting zone increases, making the material softer and easier to deform and cut. The increasing of the cutting temperature with the speed, for the tool with geometry A, can be observed in Figure 5 (a). 
Geometry A $\left(20^{\circ}\right) ; \mu=0.85$

(a)



(b)

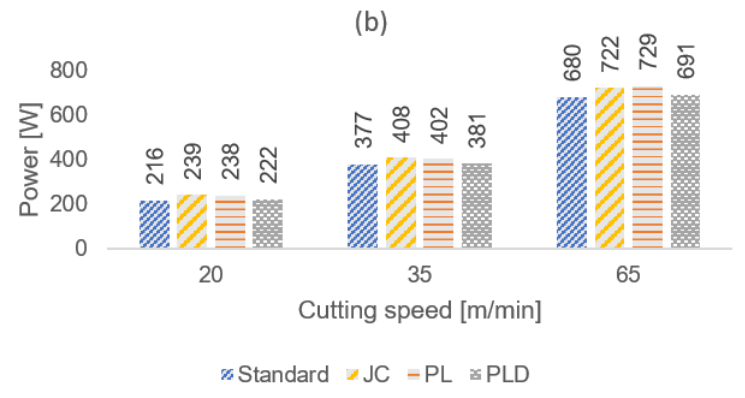

Geometry B $\left(-6 / 0^{\circ}\right) ; \mu=0.55$

(c)

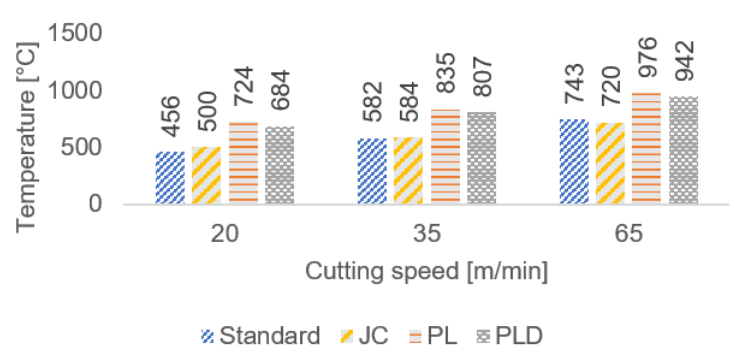

(d)

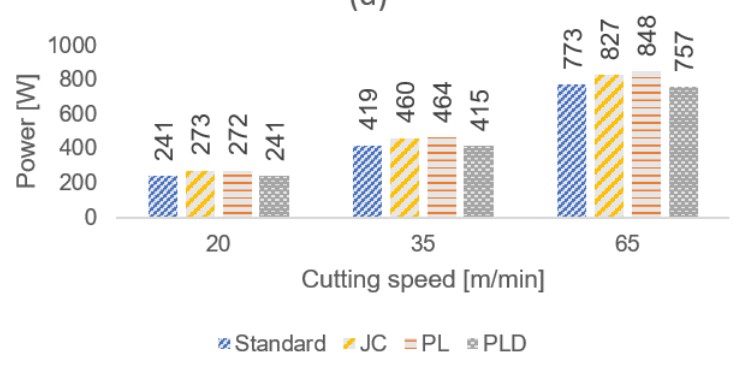

Figure 5. Simulated temperature $\left[{ }^{\circ} \mathrm{C}\right]$ for geometry $A(a)$ and geometry $B(c)$; Power consumption in machining $[W]$ for geometry $A(b)$ and geometry $B(d)$ for all the tested material models.

For geometry B, the thermal softening effect is only observed in the numerical data, which means that, that the increase of the cutting speed, decreases the cutting and feed forces, as shown in Figure 4 (c) and (d) due to the increase of the temperature in the cutting zone as indicated in Figure 5 (c). However, those results do not match the experimental machining forces' tendency. From Figure 4 (c) and (d) it is possible to observe the decreasing of the cutting force from 20 to $35 \mathrm{~m} / \mathrm{min}$, yet it increases again at $65 \mathrm{~m} / \mathrm{min}$.

Possibility, this can be explained by microstructural changes that occurred in the real Ti6Al4V alloy under machining condition, due to the coupled effect of high temperature and deformation that happens in geometry B. For this tool, a larger amount of plastic strain was induced into the metal chip (Figure 2) as well higher temperature gradient when compared with geometry A, as shown in Figure 5 (a) and (c). The tested material laws do not account for those microstructural changes that occur in real machining operation. 
The power required to cut with Geometry A (positive rake angle) was lower for all the cutting speeds when compared with Geometry B (negative-neutral rake angle) as shown in Figure 5 (b) and (d). These results match with the tendency showed by the cutting and feed force (Figure 4), since those values are lower, for all the tested conditions for Geometry A (positive rake angle) when compared with geometry B (negative-neutral rake angle).

To conclude, some remarks regarding the influence of the cutting tool geometry in the thermo-mechanical response. The tool with a positive rake angle (geometry A) tends to reduce the heat generated during machining, the cutting forces, and power, however, this tool has a weaker cutting edge (compared with geometry B), being less resilient to catastrophic failure during operation. The tool with the negative/neutral rake angle tends to reduce the overall machinability (by increasing the cutting forces, power, temperature), yet this geometry promotes a better surface to dissipate the heat and stress generated during machining. For that reason, to machine titanium alloys under high feed rate and depthof-cut, it seems reasonable to assume that geometry B it is a safer choice.

\section{Conclusion:}

In this work it was investigated the effect of the workpiece material model and parameters, specifically, the standard model provided by the simulation software, the Johnson-Cook material model, the powerlaw model and the power law model with damage, in the thermo-mechanical response (cutting forces, temperature and cutting power) obtained during Ti6AI4V machining simulations using cutting tools with distinctive rake angles, namely, a tool with a positive rake angle (geometry A) and a tool with a double rake angle (negative-neutral, designated geometry B). The material model accuracy was evaluated by calculating the percentual relative error between the experimental and numerical cutting and feed forces, as well as the average percentual error in predicting the machining forces. Some meaningful considerations can be taken after developing this work: 
- Considering all the material modelling approaches, the simulations were able to predict properly the machining forces, the maximum PRE for feed force prediction was $32 \%$, while for the cutting force was $28 \%$. The APE was lower than $23 \%$ for all the simulations. Yet, the models that were able to predict the chip morphology (PLD \& Standard) presented higher deviation from the experimental results.

- With built-in AE models, is not possible to implement a JC model coupled with a damage criterion (to simulate saw-tooth metal chips), so the only viable option is to implement this model via Fortran routines.

- Since the Ti6Al4V standard AE model (which is a PLD model inaccessible to the user), as well as the user-defined PLD, presented similar results regarding the prediction of the cutting forces and chip morphology, the user-defined PLD approach must be preferably used to simulate machining operations in Ti6AL4V since it allows the user to input different sets of parameters for the constitutive law and damage model. Additionally, seems reasonable to infer, that since only one set of parameters was used in this work to define the PLD model, other parameters available in literature may improve the attained results.

- The numerical models were an effective tool to understand the influence of the tool geometry and cutting speed into the machining response (the metal chip plastic strain, the machining forces, the cutting temperature, and power).

\section{Acknowledgements}

The authors acknowledge "Project No. 031556-FCT/02/SAICT/2017; FAMASI- Sustainable and intelligent manufacturing by machining, financed by the Foundation for Science and Technology (FCT), POCl, Portugal, in the scope of TEMA, Centre for Mechanical Technology and Automation UID/EMS/00481/2013. 


\section{References:}

[1] A. J. Festas, A. Ramos, and J. P. Davim, "Medical devices biomaterials - A review," Proc. Inst. Mech. Eng. Part L J. Mater. Des. Appl., vol. 234, no. 1, pp. 218-228, 2020, doi: $10.1177 / 1464420719882458$.

[2] K. Gupta and R. F. Laubscher, "Sustainable machining of titanium alloys: A critical review," Proc. Inst. Mech. Eng. Part B J. Eng. Manuf., vol. 231, no. 14, pp. 2543-2560, 2017, doi: $10.1177 / 0954405416634278$.

[3] S. Melkote et al., "Advances in material and friction data for modelling of metal machining," CIRP Ann. - Manuf. Technol., vol. 66, no. 2, pp. 731-754, 2017, doi: 10.1016/j.cirp.2017.05.002.

[4] C. H. Lauro, L. C. Brandão, S. L. M. R. Filho, R. A.F. Valente, and J. P. Davim, Finite Element Method in Machining Processes: A Review. Springer, 2015.

[5] L. Kandráč, I. Maňková, M. Vrabel', and J. Beňo, "Finite element simulation of cutting forces in orthogonal machining of titanium alloy Ti-6Al-4V," Appl. Mech. Mater., vol. 474, pp. 192-199, 2014, doi: 10.4028/www.scientific.net/AMM.474.192.

[6] P. Niesłony, W. Grzesik, P. Laskowski, and J. Sienawski, "Numerical and experimental analysis of residual stresses generated in the machining of Ti6A14V titanium alloy," Procedia CIRP, vol. 13, pp. 78-83, 2014, doi: 10.1016/j.procir.2014.04.014.

[7] M. Sadeghifar, R. Sedaghati, W. Jomaa, and V. Songmene, "A comprehensive review of finite element modeling of orthogonal machining process: chip formation and surface integrity predictions," Int. J. Adv. Manuf. Technol., vol. 96, no. 9-12, pp. 3747-3791, 2018, doi: 10.1007/s00170-018-1759-6.

[8] C. Shan, M. Zhang, S. Zhang, and J. Dang, "Prediction of machining-induced residual stress in orthogonal cutting of Ti6Al4V," Int. J. Adv. Manuf. Technol., vol. 107, no. 5-6, pp. 2375-2385, 2020, doi: 10.1007/s00170-020-05181-5.

[9] W. Pan, A. Kamaruddin, S. Ding, and J. Mo, "Experimental investigation of end milling of titanium alloys with polycrystalline diamond tools," Proc. Inst. Mech. Eng. Part B J. Eng. Manuf., vol. 228, no. 8, pp. 832-844, 2014, doi: 10.1177/0954405413514399.

[10] Y. Zhang, J. C. Outeiro, and T. Mabrouki, "On the selection of Johnson-Cook constitutive model parameters for Ti-6Al-4V using three types of numerical models of orthogonal cutting," in Procedia CIRP 2015, 2015, vol. 31, pp. 112-117, doi: 10.1016/j.procir.2015.03.052.

[11] F. Ducobu, E. Rivière-Lorphèvre, and E. Filippi, "Numerical contribution to the comprehension of saw-toothed Ti6Al4V chip formation in orthogonal cutting," Int. J. Mech. Sci., vol. 81, pp. 77-87, 
2014, doi: 10.1016/j.jmecsci.2014.02.017.

[12] C. Ji, Y. Li, X. Qin, Q. Zhao, D. Sun, and Y. Jin, "3D FEM simulation of helical milling hole process for titanium alloy Ti-6Al-4V," Int. J. Adv. Manuf. Technol., vol. 81, no. 9-12, pp. 1733-1742, Dec. 2015, doi: 10.1007/s00170-015-7323-8.

[13] W. Pan, S. Ding, and J. Mo, "Thermal characteristics in milling Ti6Al4V with polycrystalline diamond tools," Int. J. Adv. Manuf. Technol., vol. 75, no. 5-8, pp. 1077-1087, 2014, doi: 10.1007/s00170014-6094-y.

[14] T. H. C. Childs, P. J. Arrazola, P. Aristimuno, A. Garay, and I. Sacristan, "Ti6Al4V metal cutting chip formation experiments and modelling over a wide range of cutting speeds," J. Mater. Process. Technol., vol. 255, no. July 2017, pp. 898-913, 2018, doi: 10.1016/j.jmatprotec.2018.01.026.

[15] A. K. Parida, "Simulation and experimental investigation of drilling of Ti-6Al-4V alloy," Int. J. Light. Mater. Manuf., vol. 1, no. 3, pp. 197-205, 2018, doi: 10.1016/j.ijlmm.2018.07.001.

[16] M. Harzallah, T. Pottier, J. Senatore, M. Mousseigne, G. Germain, and Y. Landon, "Numerical and experimental investigations of Ti-6AI-4V chip generation and thermo-mechanical couplings in orthogonal cutting," Int. J. Mech. Sci., vol. 134, pp. 189-202, 2017, doi: 10.1016/j.ijmecsci.2017.10.017.

[17] F. Ducobu, E. Rivière-Lorphèvre, and E. Filippi, "Influence of the material behavior law and damage value on the results of an orthogonal cutting finite element model of Ti6Al4V," Procedia CIRP, vol. 8, pp. 379-384, 2013, doi: 10.1016/j.procir.2013.06.120.

[18] G. Ortiz-De-Zarate et al., "Evaluation of different flow stress laws coupled with a physical based ductile failure criterion for the modelling of the chip formation process of Ti-6Al-4V under broaching conditions," Procedia CIRP, vol. 82, pp. 65-70, 2019, doi: 10.1016/j.procir.2019.04.067.

[19] M. Mia et al., "Multi-objective optimization and life cycle assessment of eco-friendly cryogenic N2 assisted turning of Ti-6Al-4V," J. Clean. Prod., vol. 210, pp. 121-133, 2019, doi: 10.1016/j.jclepro.2018.10.334.

[20] U. Karaguzel, U. Olgun, E. Uysal, E. Budak, and M. Bakkal, "Increasing tool life in machining of difficult-to-cut materials using nonconventional turning processes," Int. J. Adv. Manuf. Technol., vol. 77, no. 9-12, pp. 1993-2004, 2015, doi: 10.1007/s00170-014-6588-7.

[21] M. Nouari and H. Makich, "On the Physics of Machining Titanium Alloys: Interactions between Cutting Parameters, Microstructure and Tool Wear," Metals (Basel)., vol. 4, no. 3, pp. 335-358, 2014, doi: 10.3390/met4030335.

[22] P. Stolf, J. M. Paiva, Y. S. Ahmed, J. L. Endrino, S. Goel, and S. C. Veldhuis, "The role of highpressure coolant in the wear characteristics of WC-Co tools during the cutting of Ti-6Al-4V," Wear, vol. 440-441, no. October, p. 203090, 2019, doi: 10.1016/j.wear.2019.203090. 
[23] F. Jiang, L. Yan, and Y. Rong, "Orthogonal cutting of hardened AISI D2 steel with TiAIN-coated inserts - Simulations and experiments," Int. J. Adv. Manuf. Technol., vol. 64, no. 9-12, pp. 15551563, 2013, doi: 10.1007/s00170-012-4122-3.

[24] G. R. Johnson and W. H. Cook, "A constituive Model and Data for Metals Subjected to High Strains, High Strain Rates, Temperatures and Pressures," in Proceedings of the 7th International Symposium on Ballistics, 1983, pp. 541-547.

[25] A. Iturbe et al., "Mechanical characterization and modelling of Inconel 718 material behavior for machining process assessment," Mater. Sci. Eng. A, vol. 682, pp. 441-453, 2017, doi: 10.1016/j.msea.2016.11.054.

[26] G. Ortiz-De-Zarate, A. Sela, A. Madariaga, T. H. C. Childs, and P. J. Arrazola, "Sensitivity analysis of the input parameters of a physical based ductile failure model of Ti-6Al-4V for the prediction of surface integrity," Procedia CIRP, vol. 87, pp. 533-538, 2020, doi: 10.1016/j.procir.2020.02.105.

[27] A. Sela et al., "Surface drag analysis after Ti-6Al-4V orthogonal cutting using grid distortion," Procedia CIRP, vol. 87, pp. 372-377, 2020, doi: 10.1016/j.procir.2020.02.040.

[28] J. Lu, J. Chen, Q. Fang, B. Liu, Y. Liu, and T. Jin, "Finite element simulation for Ti-6Al-4V alloy deformation near the exit of orthogonal cutting," Int. J. Adv. Manuf. Technol., vol. 85, no. 9-12, pp. 2377-2388, 2016, doi: 10.1007/s00170-015-8077-z.

[29] G. Ortiz-de-Zarate et al., "Experimental and FEM analysis of surface integrity when broaching Ti64," in Procedia CIRP 2018, 2018, vol. 71, pp. 466-471, doi: 10.1016/j.procir.2018.05.033.

[30] A. Li, J. Pang, J. Zhao, J. Zang, and F. Wang, "FEM-simulation of machining induced surface plastic deformation and microstructural texture evolution of Ti-6Al-4V alloy," Int. J. Mech. Sci., vol. 123, pp. 214-223, 2017, doi: 10.1016/j.ijmecsci.2017.02.014.

[31] A. Jain, N. Khanna, and V. Bajpai, "FE simulation of machining of Ti-54M titanium alloy for industry relevant outcomes," Measurement, vol. 129, no. July, pp. 268-276, Dec. 2018, doi: 10.1016/j.measurement.2018.07.017.

[32] V. Bajpai, I. Lee, and H. W. Park, "Finite Element Modeling of Three-Dimensional Milling Process of Ti-6Al-4V," Mater. Manuf. Process., vol. 29, no. 5, pp. 564-571, May 2014, doi: 10.1080/10426914.2014.892618.

[33] M. Calamaz, D. Coupard, and F. Girot, "A new material model for 2D numerical simulation of serrated chip formation when machining titanium alloy Ti-6Al-4V," Int. J. Mach. Tools Manuf., vol. 48, no. 3-4, pp. 275-288, Mar. 2008, doi: 10.1016/J.IJMACHTOOLS.2007.10.014.

[34] ThirdWaveSystems, AdvantEdge User's Manual, 7.501. USA: Third Wave systems, 2019.

[35] A. Davoudinejad, G. Tosello, P. Parenti, and M. Annoni, "3D finite element simulation of micro end- 
milling by considering the effect of tool run-out," Micromachines, vol. 8, no. 6, pp. 1-20, 2017, doi: $10.3390 / \mathrm{mi} 8060187$.

[36] A. Hor, F. Morel, J. Lou Lebrun, and G. Germain, "Modelling, identification and application of phenomenological constitutive laws over a large strain rate and temperature range," Mech. Mater., vol. 64, pp. 91-110, 2013, doi: 10.1016/j.mechmat.2013.05.002.

[37] N. Li and N. He, "A FEA study on mechanisms of saw-tooth chip deformation in high speed cutting of Ti-6-Al-4V alloy," in Fifth International Conference on High Speed Machining (HSM), 2006, pp. 759-767.

[38] P. Niesłony, W. Grzesik, and W. Habrat, "Experimental and simulation investigations of face milling process of Ti-6Al-4V titanium alloy," Adv. Manuf. Sci. Technol., vol. 39, no. 1, pp. 39-52, 2015, doi: 10.2478/amst-2015-0003.

[39] M. E. Merchant, "Mechanics of the metal cutting process. I. Orthogonal cutting and a type 2 chip," J. Appl. Phys., vol. 16, no. 5, pp. 267-275, 1945, doi: 10.1063/1.1707586.

[40] P. N. Rao, Manufacturing Technology Volume 2: Metal Cutting and Machine Tools. McGraw Hill, 2013.

[41] Niharika, B. P. Agrawal, I. A. Khan, and Z. A. Khan, "Effects of Cutting Parameters on Quality of Surface Produced by Machining of Titanium Alloy and Their Optimization," Arch. Mech. Eng., vol. 63, no. 4, pp. 531-548, 2016, doi: 10.1515/meceng-2016-0030. 